Tohoku J. Exp. Med., 2007, 212, 71-80

\title{
Difference in Quality of Life According to the Severity of Malocclusion in Japanese Orthodontic Patients
}

\author{
Mayumi Tajima, ${ }^{1}$ Masahiro Kohzuki, ${ }^{2}$ Shiori Azuma, ${ }^{3}$ Shuichi Saeki, ${ }^{3}$ \\ Makiko Meguro $^{2}$ and JunJi Sugawara ${ }^{1}$ \\ ${ }^{1}$ Department of Orthodontics and Dentofacial Orthopedics, Tohoku University Graduate School of \\ Dentistry, Sendai, Japan \\ ${ }^{2}$ Department of Internal Medicine and Rehabilitation Science, Tohoku University Graduate School \\ of Medicine, Sendai, Japan \\ ${ }^{3}$ Department of Oral Dysfunction Science, Tohoku University Graduate School of Dentistry, \\ Sendai, Japan
}

Tajima, M., Kohzuki, M., Azuma, S., Saeki, S., Meguro, M. and Sugawara, J. Difference in Quality of Life According to the Severity of Malocclusion in Japanese Orthodontic Patients. Tohoku J. Exp. Med., 2007, 212 (1), 71-80 — Although quality of life (QOL) assessment is important in dentistry, it has not been fully investigated in orthodontic patients. We investigated the health-related generic QOL (entire body health) and disease specific QOL (oral health) in adult patients with malocclusions at the first visit. One hundred and twenty-seven orthodontic patients and 66 persons with normal occlusion were recruited for the study. The subjects were divided into the three following groups based on their treatment: 61 patients in need of surgical correction (SURG), 66 patients in need of non-surgical correction (NONS), and 66 control subjects with normal occlusion. Their dentofacial morphology was assessed using a specific Severity Score (SS), which was set up originally based on their cephalometric radiographs and their plaster models of arrangement of their teeth. The subjects also completed a generic QOL assessment questionnaire, the SF-36, and two disease-specific QOL instruments. The patients with malocclusions, especially SURG, had lower disease-specific QOL, although the generic QOL was equal to that of control subjects. Furthermore, in patients with the same severity of dentofacial deformities, especially SS 4 and SS 5, the borderline cases of surgical correction and non-surgical correction, there were differences between SURG and NONS in some items of the QOL. The severity of malocclusion evidently plays an important role in patients' choice of treatment, but also QOL appeared to play a significant role. The QOL assessment may contribute to the selection of the best treatment for improving QOL, especially for borderline cases with moderate degrees of orthodontic abnormality. health-related QOL; malocclusions; surgical correction; Severity Score; SF-36

(C) 2007 Tohoku University Medical Press

The importance of quality of life (QOL) has received widespread acceptance in medicine (Han et al. 2006). Oral diseases and disorders are high- ly prevalent and give rise to not only physical, but also economic, social, and psychological problems. They impair QOL significantly and may

Received December 4, 2006; revision accepted for publication March 30, 2007.

Correspondence: Masahiro Kohzuki, M.D. Ph.D., Department of Internal Medicine \& Rehabilitation Science, Tohoku University Graduate School of Medicine, 1-1 Seiryo-cho, Aoba-ku, Sendai 980-8574, Japan.

e-mail: kohzuki@mail.tains.tohoku.ac.jp 
affect various aspects of life including function, appearance, and interpersonal relationships in a large number of individuals (Gift and Redford 1992). The need for a comprehensive approach to study the social and psychological impact of oral diseases was first realized in the late 1980s (Gift and Redford 1992). The growing demand for measures of oral health-related QOL has led to the development of instruments such as the Oral Health Impact Profile (OHIP) (Slade 1994, 1997, 1998), the Social Impacts of Dental Disease (Cushing et al. 1986), the Geriatric Oral Health Assessment Index (Athison and Dolan 1990); the Dental Impact Profile (Strauss and Hunt 1993); the Oral Health-Related Quality of Life Measure (Kressin et al. 1996); the Dental Impact of Daily Living (DIDL) (Laeo and Sheiham 1996); and the Subjective Oral Health Status Indicators (SOHSI) (Locker and Miller 1994).

However, orthodontic treatment is different from most other medical interventions, in that it often aims only to correct variation from an arbitrary norm (O'Brien et al. 1998). The context of outcome assessment in orthodontic treatment is different from the conventional understanding in health care, where treatment does not necessarily make patients feel "well" or extend their lives (Cunningham et al. 2000). The majority of measures developed in the field of dentistry are not applicable to orthodontic patients, primarily because most orthodontic conditions are asymptomatic and relate to aesthetics rather than features such as pain or discomfort (O'Brien et al. 1998).

The research on the outcomes of orthodontic treatment has tended to concentrate on traditional indices and measurements such as cephalometric measures before and after treatment, or morbidity by measuring root resorption following treatment (Cunningham and Hunt 2001). These clinical indicators are important still but should be supplemented with health related quality of life (HRQL) measures for two main reasons (Bennett and Phillips 1999): firstly, the HRQL outcome does not necessarily correlate with objective findings, and, secondly, patients' ratings of outcome may not correlate with those of clinicians. It is for these reasons that self-reported HRQL instruments should be developed and used to achieve a better understanding of the patients' perspectives.

The relationship between orthodontics and HRQL has not been fully investigated in orthognathic patients. Although one of the reasons frequently stated for undertaking orthodontic treatment is for improvement in aesthetics and subsequent enhancement of psycho-social wellbeing, even that issue is open to some debate (Shaw et al. 1986). In the present study, we compared the QOL of orthognathic patients with those without orthognathic surgery before the treatment. To achieve the above aim of this investigation, the following two hypotheses were tested:

1. There are significant differences in QOL among orthognathic patients, non- orthognathic patients and persons with normal occlusion.

2. There are characteristic factors that influence the choice of treatment other than the severity of the malocclusion.

\section{Material ANd Methods}

\section{Subjects}

New patients visiting Tohoku University Hospital from July 2003 to April 2005 were asked to complete three valid health status measures; The Short Form-36 (Ware and Sherbourne 1992; Ware 1993), The SOHSI (Locker and Miller 1994) and The Orthognathic Quality of Life Questionnaire (Cunningham et al. 2000, 2002) before discussing their orthodontic treatment with each one's doctor. Patients with no other co-morbidities except malocclusions who chose to have treatment at Tohoku University Hospital after the interview were included in the study. A total of 127 adult patients with malocclusions, and 66 persons with normal occlusion gave consented to take part in this study. Persons with normal occlusion had good maxillomandibular relation, especially good bilateral canine relations and molar relations, and had adequate dental axis, overjet and overbite, and had no arch length discrepancy (ALD) or minor $\operatorname{ALD}(<2 \mathrm{~mm})$.

The patients were divided into two groups based on their treatment plans; namely, the subjects who required surgical intervention (SURG; $n=61$ ) and those who did not require surgery (NONS; $n=66$ ). Patients had a discussion with each one's doctor about their treatment plans, then decided their treatment plans. When the 
patient's morphological deformity was large and constitution of neutral occlusion is impossible in the present patient's maxillomandibular relation (Severity Score [SS] 6-9), each doctor suggested surgical intervention plan. In cases that patient's morphological deformity was not severe and constitution of neutral occlusion was possible in the present maxillomandibular relation (SS 1-3), each doctor suggested non-surgical intervention plan. When the patient's morphological deformity was moderate and constitution was somehow possible in the present patient's maxillomandibular relation using orthodontic implant anchors (SS 4-5), each doctor suggested both non-surgical and surgical intervention plan. Therefore, SURG is the group of patients who were suggested surgical intervention and accepted the surgery. NONS is the group of patients who were not suggested surgical intervention, or who were suggested surgical intervention but did not accept surgery with modelate morphological deformities and selected non-surgical intervention with orthodontic implant anchors. Persons with normal occlusion served as the control group (CONT; $n=66$ ). The characteristics of the subjects are shown in Table 1.

\section{Measures}

Three valid health status measures (The Short Form-36, The Subjective Oral Health Indicators and The Orthognathic Quality of Life Questionnaire) were used to evaluate the patients' subjective QOL. We also devised a SS system to assess the patients' morphological deformity so that the patients' subjective assessments could be compared with our objective assessments.

The Short Form-36 (SF-36). The SF-36 is currently one of the most widely used generic health status measures, and is often used alongside condition-specific instruments to assess the validity and responsiveness (Ware and Sherbourne 1992; Ware 1993; Garratt et al.
1996). The instrument consists of 36 items divided into eight subscales, namely: physical functioning, social functioning, role functioning-physical, role functioningemotional, vitality, mental health, bodily pain and general health perceptions. Each scale is scored 0-100 where 0 is the worst possible and 100 the best possible health. There is ample evidence for the validity, reliability, and responsiveness of SF-36 in different populations (Brazier et al. 1993; Garratt et al. 1994; Garratt et al. 1996).

The SOHSI. Disease specific QOL was measured by SOHSI. The SOHSI takes as its theoretical basis Locker's conceptual model of oral health (Locker 1998). SOHSI is useful for descriptive oral health surveys of general populations. The instrument comprises the following scales: "ability to chew", "ability to speak", "oral and facial pain symptoms", "other oral symptoms", "eating impact scale", "communication/social relations impact scale", "activities of daily living scale" and "worry/concern scale". The response format varies with each scale. The scales 'ability to chew', 'ability to speak', 'oral and facial pain symptoms' and 'other oral symptoms' all have yes / no dichotomous responses. The "eating impact scale", "activities of daily living scale" and the "worry/concern scale" all have 5-point rating scales of the frequency of occurrence of each item of the categories: all the time (scored 5), very often (scored 4), fairly often (scored 3), sometimes (scored 2) and never (scored 1). These indicators are useful for descriptive oral health surveys of general populations (Locker and Miller 1994). All questions were administered as a selfcompleted questionnaire.

The Orthognathic Quality of Life Questionnaire $(O Q L Q)$. Disease specific QOL was also measured by the Orthognathic Quality of Life Questionnaire (OQLQ) (Cunningham et al. 2000). The instrument was developed for orthognathic patients and consists of 22 statements marked on a 4-point scale according to how much

TABLE 1. Sample characteristics.

\begin{tabular}{llccc}
\hline & & SURG & NONS & CONT \\
\hline \multirow{2}{*}{ Sex } & Male & $21(34.4 \%)$ & $12(18.2 \%)$ & $28(42.4 \%)$ \\
& Female & $40(65.6 \%)$ & $54(81.8 \%)$ & $38(57.6 \%)$ \\
\multirow{2}{*}{ Age $(\mathrm{y})$} & Mean & $24.8 \mathrm{y}$ & $22.8 \mathrm{y}$ & $22.0 \mathrm{y}$ \\
& Range & $16 \sim 40 \mathrm{y}$ & $16 \sim 41 \mathrm{y}$ & $19 \sim 31 \mathrm{y}$ \\
\multirow{2}{*}{ Sum } & & 61 persons & 66 persons & 66 persons \\
\hline
\end{tabular}

SURG, surgical correction; NONS, non-surgical correction; CONT, control subjects with normal occlusion. 
the issue covered by the statement bothers the respondent. The 22 items contribute to four dimensions: "social aspects of dentofacial deformity", "facial aesthetics", "oral function", "awareness of dentofacial aesthetics". OQLQ dimensions are scored so that lower scores indicate a better quality of life and higher scores represents a poorer quality of life. The $100 \mathrm{~mm}$ visual analogue scale (VAS) was marked from 0 to 10 ; where the respondents were asked to rate how they felt about their dental and facial appearance and oral function, with 0 being "no problem" and 10 being "the worst problem imaginable". The OQLQ showed good reliability (Cunningham et al. 2000), validity and responsiveness (Cunningham et al. 2002).

Assessment of patients' morphological deformities

To assess the patients' morphological deformities, we set up a SS for each patient based on their cephalometric radiographs which were traced and lined, and the angular and plaster model measurements were assessed. The SS were used to assess the patients' dentofacial deformities, and defined in Table 2.

\section{Data analysis}

Comparisons of QOL among SURG, NONS and CONT, comparisons of the generic QOL measured by SF-36 between the Japanese standard value and SURG, NONS and CONT, comparisons of Severity Scores among SURG, NONS and CONT, and comparisons of the QOL between SURG and NONS in SS 4 and SS 5 were made by the Mann Whitney's U-test, and the data were expressed as mean \pm S.D. The Bonferroni adjustment was used for $p$ values to control the type I error. The statistical analysis in the present study was performed using the statistical software SPSS version 11.0J (SPSS Inc., Chicago, IL, USA).

The study protocol was approved by the ethical committee of Tohoku University and all the subjects gave informed consent.

\section{Results}

\section{Comparisons of QOL among SURG, NONS} and CONT

The results of the generic QOL measured by SF-36 are shown in Table 3. In all domains of SF-36, there were no significant differences among SURG, NONS, and CONT. Furthermore, data of the Japanese standard SF-36 value under 29 years old are shown in Table 3. There were no significant differences between the Japanese standard value and SURG, NONS and CONT.

The results of disease specific QOL measured by SOHSI are shown in Table 3. In most domains of SOHSI except for Eating impact scale (sum) and Activities daily impact scale (\%, sum),

TABLE 2. Definition of the Severity Score.

\begin{tabular}{|c|c|c|}
\hline \multirow[t]{2}{*}{ Dental } & Arch length discrepancy (ALD) & $0:$ Deficiency $\leq 7-8 \mathrm{~mm}$ \\
\hline & & $\begin{array}{l}\text { 1: Deficiency }>7-8 \mathrm{~mm} \\
(7-8 \mathrm{~mm}: \text { patients' own premolar size })\end{array}$ \\
\hline \multirow[t]{4}{*}{ Skeletal } & Anteroposterior jaw discrepancy (AD) & $0:$ Discrepancy $\leq 1 \mathrm{SD}$ \\
\hline & & 1: $1 \mathrm{SD}<$ Discrepancy $\leq 2 \mathrm{SD}$ \\
\hline & & 2: $2 \mathrm{SD}<$ Discrepancy $\leq 3 \mathrm{SD}$ \\
\hline & & 3: Discrepancy $>3$ SD \\
\hline \multirow[t]{4}{*}{ Skeletal } & Vertical jaw discrepancy (VD) & $0:$ Discrepancy $\leq 1 \mathrm{SD}$ \\
\hline & & 1: $1 \mathrm{SD}<$ Discrepancy $\leq 2 \mathrm{SD}$ \\
\hline & & 2: $2 \mathrm{SD}<$ Discrepancy $\leq 3 \mathrm{SD}$ \\
\hline & & 3: Discrepancy $>$ 3SD \\
\hline \multirow[t]{3}{*}{ Skeletal } & Transversal jaw discrepancy (TD) & 0: Symmetry \\
\hline & & 1: Asymmetry $\leq 5 \mathrm{~mm}$ \\
\hline & & 2: Asymmetry $>5 \mathrm{~mm}$ \\
\hline \multicolumn{2}{|c|}{ Severity score $=\Sigma($ ALD + AD + VD + TD $)$} & (Minimum: 0 Maximum: 9) \\
\hline
\end{tabular}


there were significant differences between SURG and CONT $(p<0.001$ or 0.01 or 0.05$)$. In contrast, between NONS and CONT, there were significant differences in "ability to speak", "Communication/social relations impact scale (\%) (sum)" and "Worry/concern scale (\%) (sum)" of

TABle 3. Comparisons of QOL among SURG, NONS and CONT.

\begin{tabular}{|c|c|c|c|c|c|}
\hline Measure & Domain & SURG $(n=61)$ & NONS $(n=66)$ & $\operatorname{CONT}(n=66)$ & $\begin{array}{l}\text { Japanese standard } \\
\text { value }(n=644)\end{array}$ \\
\hline \multirow[t]{9}{*}{ SF-36 } & Physical functioning & $95.0 \pm 7.8$ & $96.4 \pm 5.6$ & $95.4 \pm 7.1$ & $94.4 \pm 9.4$ \\
\hline & Role functioning physical & $86.9 \pm 25.7$ & $94.3 \pm 16.3$ & $93.2 \pm 15.5$ & $91.9 \pm 20.8$ \\
\hline & Bodily pain & $82.4 \pm 19.7$ & $85.2 \pm 17.5$ & $86.6 \pm 17.5$ & $79.8 \pm 21.2$ \\
\hline & Social functioning & $84.7 \pm 22.1$ & $88.8 \pm 16.2$ & $88.3 \pm 16.7$ & $86.5 \pm 18.9$ \\
\hline & General health perceptions & $62.9 \pm 19.6$ & $64.4 \pm 15.0$ & $63.6 \pm 13.8$ & $71.3 \pm 18.2$ \\
\hline & Vitality & $56.1 \pm 215$ & $57.1 \pm 20.4$ & $64.5 \pm 16.7$ & $64.9 \pm 19.6$ \\
\hline & Role functioning emotional & $80.2 \pm 34.2$ & $81.2 \pm 32.7$ & $78.6 \pm 32.5$ & $84.3 \pm 27.5$ \\
\hline & Mental health & $66.0 \pm 19.8$ & $69.7 \pm 16.3$ & $72.5 \pm 18.6$ & $70.5 \pm 18.3$ \\
\hline & & SURG $(n=61)$ & NONS $(n=65)$ & CONT $(n=64)$ & \\
\hline \multirow[t]{12}{*}{ SOHSI } & Ability to chew & $9.0 \pm 21.0^{* *}$ & $3.6 \pm 10.8$ & $0.3 \pm 2.1$ & \\
\hline & Ability to speak & $49.2 \pm 43.3^{* * *++}$ & $28.2 \pm 37.8^{*}$ & $13.0 \pm 21.9$ & \\
\hline & Oral and facial pain symptoms & $23.2 \pm 23.2^{* *}$ & $15.4 \pm 16.2$ & $12.1 \pm 15.5$ & \\
\hline & Other oral symptoms & $20.2 \pm 18.6^{* * *++}$ & $12.0 \pm 12.1$ & $9.4 \pm 11.0$ & \\
\hline & Eating impact scale (\%) & $47.0 \pm 36.2^{*}$ & $39.9 \pm 34.2$ & $29.8 \pm 28.1$ & \\
\hline & Eating impact scale (sum) & $12.9 \pm 1.8$ & $13.1 \pm 2.0$ & $13.6 \pm 1.6$ & \\
\hline & $\begin{array}{l}\text { Communication/social relations } \\
\text { impact scale }(\%)\end{array}$ & $46.7 \pm 32.4^{* * *++}$ & $32.2 \pm 27.3^{* * *}$ & $11.4 \pm 18.7$ & \\
\hline & $\begin{array}{l}\text { Communication/social relations } \\
\text { impact scale (sum) }\end{array}$ & $16.3 \pm 3.6^{* * *++}$ & $18.0 \pm 2.1^{* *}$ & $19.4 \pm 1.1$ & \\
\hline & $\begin{array}{l}\text { Activities daily living impact scale } \\
(\%)\end{array}$ & $23.8 \pm 31.8$ & $16.4 \pm 27.5$ & $14.4 \pm 27.5$ & \\
\hline & $\begin{array}{l}\text { Activities daily living impact scale } \\
\text { (sum) }\end{array}$ & $27.5 \pm 4.5$ & $28.6 \pm 2.5$ & $28.8 \pm 2.4$ & \\
\hline & Worry/concern impact scale (\%) & $87.7 \pm 25.3^{* * *}$ & $83.3 \pm 30.8^{* * *}$ & $46.2 \pm 42.3$ & \\
\hline & Worry/concern impact scale (sum) & $6.0 \pm 2.3^{* * *+}$ & $7.0 \pm 1.9^{* * * *}$ & $8.8 \pm 1.2$ & \\
\hline \multirow[t]{5}{*}{ OQLQ } & & SURG $(n=61)$ & NONS $(n=65)$ & CONT $(n=66)$ & \\
\hline & Social aspects & $13.4 \pm 10.8^{* * *+++}$ & $6.0 \pm 6.8$ & $4.3 \pm 5.0$ & \\
\hline & Dento-facial aesthetics & $13.8 \pm 5.9^{* * *+++}$ & $8.7 \pm 5.4^{*}$ & $6.2 \pm 4.6$ & \\
\hline & Function & $6.7 \pm 5.4^{* * *++}$ & $4.0 \pm 4.6^{* *}$ & $1.1 \pm 2.3$ & \\
\hline & Awareness of dentofacial aesthetics & $6.8 \pm 5.2^{* *+}$ & $4.5 \pm 4.0$ & $4.3 \pm 4.0$ & \\
\hline
\end{tabular}

Results and data of Japanese standard value under 29 years old of SF 36 expressed as mean \pm S.D. *Significantly different from CONT by Mann Whitney's U-test; $p<0.05$, Bonferroni adjustment. ** Significantly different from CONT by Mann Whitney's U-test; $p<0.01$, Bonferroni adjustment. **** Significantly different from CONT by Mann Whitney's U-test; $p<0.001$, Bonferroni adjustment. ${ }^{+}$Significantly different from NONS by Mann Whitney's U-test; $p<0.05$, Bonferroni adjustment. ${ }^{++}$Significantly different from NONS by Mann Whitney's U-test; $p<0.01$, Bonferroni adjustment. ${ }^{++}$Significantly different from NONS by Mann Whitney's U-test; $p<0.001$, Bonferroni adjustment. 
SOHSI ( $p<0.001$ or 0.01 or 0.05 ), and between SURG and NONS, in "ability to speak", "other oral symptoms", "communication/social relations impact scale (\%) (sum)" and "worry/concern scale (sum)" of SOHSI ( $p<0.01$ or 0.05 ).

The results of the disease specific QOL measured by OQLQ are also shown in Table 3. In SURG, in all domains of OQLQ, there were significant differences compared with CONT and

Severity Score

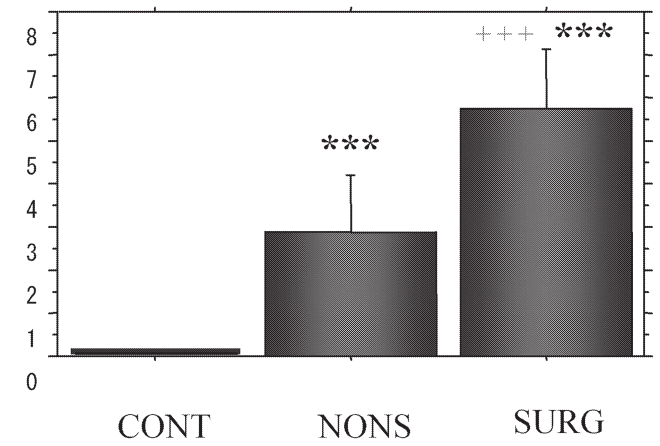

Fig. 1. Validity of the Severity Score.

Comparisons of Severity score among SURG, NONS, and CONT were expressed.

Results expressed as mean \pm S.D.

**** Significantly different from CONT by Mann Whitney's U-test; $p<0.001$, Bonferroni adjustment.

${ }^{+++}$Significantly different from NONS by Mann Whitney's U-test; $p<0.001$, Bonferroni adjustment.
NONS $(p<0.001$ or 0.01 or 0.05$)$. However, between NONS and CONT only in the domains of "dento-facial aesthetics" and "function" of OQLQ were there significant differences $(p<$ $0.05,0.01)$.

\section{Validity of SS}

Comparisons of SS among SURG, NONS and CONT were shown in Fig. 1. Data of SS are expressed as mean \pm S.D. There were significant differences among the three groups $(p<0.001)$. As the SS of SURG was significantly larger than that of NONS and the SS of NONS was significantly larger than that of CONT, it is certain that the SS is good indicator which shows the degree of patients' morphological deformities.

\section{The SS and number of patients}

Correlation of SS and number of patients are shown in Fig. 2.

\section{Comparisons of QOL between SURG and NONS in SS 4 and SS 5}

The results of the QOL of patients with SS 4 and SS 5 are shown in Table 4. Only in the domain of 'awareness of dentofacial aesthetics' of OQLQ, were there significant differences between SURG and NONS both in SS 4 and SS 5 ( $p<$ $0.05)$. In contrast, there were significant differences between SURG and NONS in the domains

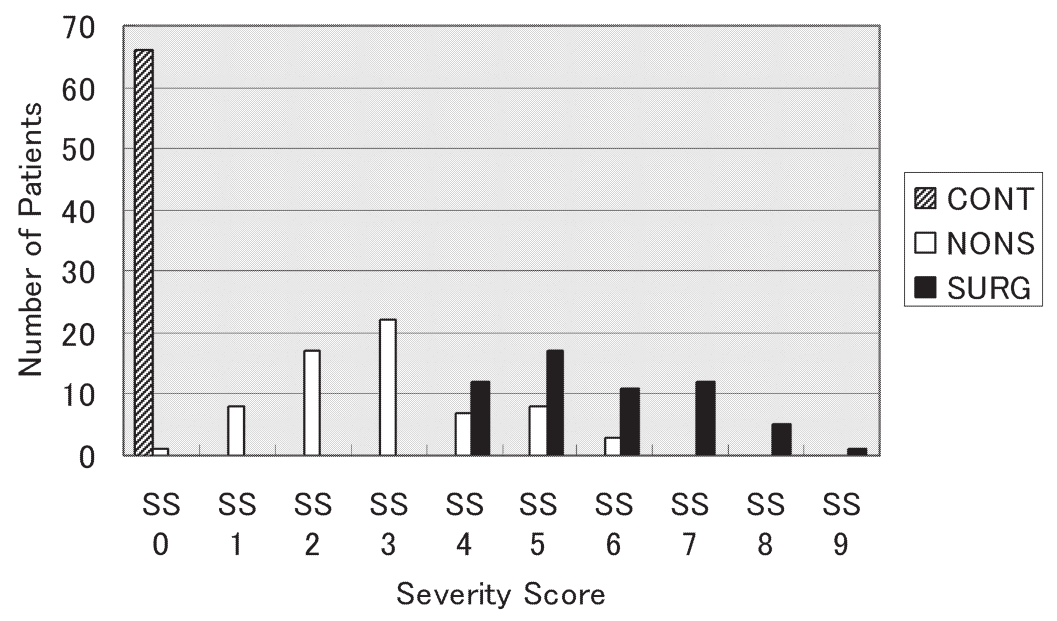

Fig. 2. Severity Score (SS) and number of patients.

Vertical axis is expressed number of patients and horizontal axis is expressed the SS. 
TABle 4. Comparisons of QOL between SURG and NONS in Severity Score 4 and 5.

\begin{tabular}{|c|c|c|c|c|c|}
\hline \multirow{2}{*}{ Measure } & \multirow{2}{*}{ Domain } & \multicolumn{2}{|c|}{ Severity Score 4} & \multicolumn{2}{|c|}{ Severity Score 5} \\
\hline & & SURG $(n=12)$ & NONS $(n=7)$ & SURG $(n=17)$ & NONS $(n=8)$ \\
\hline \multirow[t]{8}{*}{ SF-36 } & Physical functioning & $92.9 \pm 6.9$ & $94.3 \pm 11.3$ & $93.8 \pm 12.3$ & $96.8 \pm 2.6$ \\
\hline & Role functioning physical & $85.4 \pm 19.8$ & $100 \pm 0.0$ & $79.4 \pm 36.7$ & $96.9 \pm 8.8$ \\
\hline & Bodily pain & $79.2 \pm 20.5$ & $88.1 \pm 15.3$ & $84.3 \pm 18.8$ & $89.3 \pm 12.7$ \\
\hline & Social functioning & $67.9 \pm 14.0$ & $63.4 \pm 16.7$ & $60.2 \pm 22.0$ & $59.5 \pm 17.1$ \\
\hline & General health perceptions & $67.0 \pm 20.7$ & $73.7 \pm 12.8$ & $64.9 \pm 20.7$ & $75.5 \pm 14.1$ \\
\hline & Vitality & $74.9 \pm 40.6$ & $90.4 \pm 25.3$ & $78.3 \pm 35.3$ & $95.8 \pm 12.0$ \\
\hline & Role functioning emotional & $79.0 \pm 18.1^{*}$ & $94.6 \pm 14.3$ & $87.3 \pm 20.3$ & $90.5 \pm 14.7$ \\
\hline & Mental health & $60.4 \pm 24.6$ & $58.5 \pm 14.1$ & $56.5 \pm 21.1$ & $66.9 \pm 16.5$ \\
\hline \multirow[t]{12}{*}{ SOHSI } & Ability to chew & $6.9 \pm 13.2$ & $0.0 \pm 0.0$ & $6.9 \pm 16.7$ & $12.5 \pm 19.4$ \\
\hline & Ability to speak & $61.1 \pm 48.9$ & $28.6 \pm 35.6$ & $39.2 \pm 37.7$ & $37.5 \pm 41.5$ \\
\hline & Oral and facial pain symptoms & $23.8 \pm 18.6$ & $12.2 \pm 12.9$ & $21.8 \pm 22.1$ & $16.1 \pm 19.4$ \\
\hline & Other oral symptoms & $16.7 \pm 13.0$ & $18.6 \pm 13.5$ & $21.2 \pm 22.9$ & $13.8 \pm 13.0$ \\
\hline & Eating impact scale (\%) & $41.7 \pm 37.9$ & $23.8 \pm 37.1$ & $49.0 \pm 39.3$ & $33.3 \pm 25.2$ \\
\hline & Eating impact scale (sum) & $12.7 \pm 1.9$ & $13.7 \pm 2.2$ & $12.8 \pm 2.2$ & $14.0 \pm 0.8$ \\
\hline & $\begin{array}{l}\text { Communication/social relations } \\
\text { impact scale }(\%)\end{array}$ & $45.8 \pm 27.9$ & $42.9 \pm 27.8$ & $41.2 \pm 36.3$ & $25.0 \pm 23.1$ \\
\hline & $\begin{array}{l}\text { Communication/social relations } \\
\text { impact scale (sum) }\end{array}$ & $16.6 \pm 2.8$ & $17.7 \pm 2.3$ & $15.0 \pm 3.6$ & $18.4 \pm 1.8$ \\
\hline & $\begin{array}{l}\text { Activities daily living impact scale } \\
(\%)\end{array}$ & $20.8 \pm 37.7$ & $0.0 \pm 0.0$ & $20.6 \pm 31.5$ & $16.7 \pm 25.2$ \\
\hline & $\begin{array}{l}\text { Activities daily living impact scale } \\
\text { (sum) }\end{array}$ & $27.4 \pm 5.0^{*}$ & $30.0 \pm 0.0$ & $27.4 \pm 5.2$ & $28.8 \pm 1.8$ \\
\hline & Worry/concern impact scale (\%) & $85.7 \pm 24.4$ & $85.7 \pm 24.4$ & $88.2 \pm 21.9$ & $81.3 \pm 37.2$ \\
\hline & Worry/concern impact scale (sum) & $6.8 \pm 1.9$ & $6.4 \pm 2.6$ & $6.6 \pm 1.7$ & $7.1 \pm 2.2$ \\
\hline \multirow[t]{4}{*}{ OQLQ } & Social aspects & $15.3 \pm 12.2$ & $6.7 \pm 9.4$ & $10.2 \pm 9.4$ & $5.8 \pm 7.8$ \\
\hline & Dento-facial aesthetics & $14.8 \pm 5.3$ & $9.4 \pm 7.1$ & $12.6 \pm 6.8$ & $10.1 \pm 7.6$ \\
\hline & Function & $7.3 \pm 6.7$ & $2.6 \pm 3.2$ & $4.9 \pm 4.2$ & $4.5 \pm 5.3$ \\
\hline & Awareness of dentofacial aesthetics & $8.3 \pm 4.9^{*}$ & $2.0 \pm 2.8$ & $6.6 \pm 5.2^{*}$ & $1.9 \pm 3.2$ \\
\hline
\end{tabular}

Results expressed as mean \pm S.D.

*Significantly different from CONT by Mann Whitney's U-test; $p<0.05$.

of "Role Functioning Emotional" of SF-36 and in the domains of "Activities daily living impact scale (sum)" of SOHSI in SS 4.

\section{Discussion}

The patients with malocclusions, especially those in need of surgical correction, had lower disease-specific QOL, although the generic QOL was equal to that of the controls. Furthermore, in patients with the same severity of dentofacial deformities, especially SS 4 and SS 5, the borderline cases of surgical correction and non-surgical correction, there were differences between SURG and NONS in some items of the QOL.

This is the first report of using various QOL measures for adult patients with malocclusions who planned to have surgical correction or nonsurgical correction at the time of the patients' first visit. This is also the first report showing the differences of QOL between patients with malocclu- 
sions and persons with normal occlusion.

Among patients with the same degree of dentofacial deformity, some selected surgical correction and others selected non-surgical correction. Accordingly, it is considered that both preferences of the orthodontists and those of the patients may have affected the treatment choice.

If a patient's SS is large or small, the treatment course will be surgical correction or nonsurgical correction, respectively independently of the QOL. However, in borderline cases such as intermediate SS 4 and SS 5, both surgical correction and non-surgical correction are options, and the treatment course is selected by the patients themselves. Since patients with a low disease specific QOL may expect greater improvement from orthodontic treatment, such patients may choose surgical correction. As a matter of fact, significant improvement in patients' disease specific QOL after orthognathic surgery has been reported (Cunningham and Hunt 1996; Bennett and Phillips 1999; Bertolini et al. 2000; Cunningham et al. 2002; Nardi et al. 2003; Rispoli et al. 2004).

The generic QOL of orthognathic surgery patients measured by SF-36 in England, prior to surgery and after removal of the orthodontic appliances, showed the same levels of generic QOL measured by SF-36 in SURG, NONS and CONT as those in the present study at the time of the patients' first visit (Cunningham et al. 2002). Furthermore, there were no significant differences between the Japanese standard value and SURG, NONS and CONT, and the QOL of all three groups was equal to that of general Japanese under 29 years old (Fukuhara et al. 2001). The reason why the levels of generic QOL measured by SF-36 were matched might that the subjects had no other problems except for oral ones.

Compared with the mean levels of diseasespecific QOL measured by SOHSI in the 18-29 age group of the general population from New York, the mean levels of disease-specific QOL measured by SOHSI in the SURG and NONS in the present study at the time of patients' first visit were lower, except for the domains of oral and facial pain symptoms and other oral symptoms
(Locker and Miller 1994). This may be partly because we targeted patients with malocclusions whose mean age was 24.8 in SURG and 22.8 in NONS, each mean age of which was included in the 18-29 age group, but since there were age ranges of 16-40 in SURG and 16-41 in NONS, about $21 \%$ of the patients were over the age of 30 . Secondly, the patients with malocclusions had various ranges of dentofacial deformity. However, the patients with malocclusions had fewer problems with chewing, oral and facial pain and symptoms compared with the older people in New York who also had problems related to tooth loss and pain or symptoms of periodontal disease.

In the study by Cunningham et al. (2002), the disease-specific QOL measured by OQLQ in the orthognathic surgery patients prior to treatment showed the same mean levels of diseasespecific QOL as those of the present patients at the time of patients' first visit. This is likely because the mean ages of the orthognathic surgery patients prior to treatment were similar, and the research moments were also nearly matched.

NONS and CONT showed higher mean values of disease-specific QOL compared with SURG. NONS had lower severity of malocclusions and CONT had normal occlusion, the mean values of disease-specific QOL were markedly higher compared with the orthognathic surgery patients prior to treatment in the study of Cunningham et al. (2002). However, Cunningham et al. (2002) did not examine differences compared with persons with normal occlusion or patients with malocclusions requesting non-surgical correction. Accordingly, a detailed comparison can not be made between the two studies.

Quality of life changes have been studied mainly in relation to orthognathic surgery but not in orthodontic non-surgical treatment (Kiyak et al. 1986; Flanary et al. 1990; Cunningham et al. 1996; Hatch et al. 1998; Bennett and Phillips 1999). A longitudinal study of pre- and postoperative psychological characteristics of patients that underwent orthognathic treatment confirmed the perception that the patients benefit psychologically from the improved facial and dental appearance, and an associated increase in self-confidence 
was also found (Kiyak et al. 1982, 1984). In another study, high levels of post-operative satisfaction and healthy psychological adjustment were found, which led the authors to conclude that orthognathic treatment appeared to have a positive impact on QOL (Flanary et al. 1990). It therefore seems reasonable to assume that orthognathic treatment would be associated with improvements in HRQL. Moreover, it has been proposed that a combination of condition-specific and generic measures would be needed for assessments of orthognathic patients and it is likely that future research will focus on the development of appropriate instruments (Bennett and Phillips 1999).

There are some limitations in this study. As the age and the sex rate of three groups are different, it might be possible that there are more significant differences between patients with malocclusions and persons with normal occlusion in this report. It will be necessary to examine the QOL of patients after orthodontic treatment and assess the results longitudinally in the future. Especially in borderline cases, it will be necessary to elucidate whether the difference in the improvement of QOL between surgical and nonsurgical correction is significant.

In summary, the patients with malocclusions, especially those in need of surgical correction, had lower disease-specific QOL, although the generic QOL was equal to that of the controls. Furthermore, in patients with the same severity of dentofacial deformities, especially SS 4 and SS 5, the borderline cases of surgical correction and non-surgical correction, there were differences between SURG and NONS in some items of the QOL. The severity of malocclusion evidently plays an important role in patients' choice of treatment, but also QOL appeared to play a significant role. The QOL assessment may contribute to the selection of the best treatment for improving QOL, especially for borderline cases with moderate degrees of orthodontic abnormality.

\section{References}

Athison, K.A. \& Dolan, T.A. (1990) Development of the geri- atric oral health assessment index. J. Dent. Educ., 54 680-687.

Bennett, M.E. \& Phillips, C.L. (1999) Assessment of healthrelated quality of life for patients with severe skeletal deformity: a review of issues. Int. J. Adult. Orthod. Orthognath. Surg., 14, 65-75.

Bertolini, F., Russo, V. \& Sansebastiano, G. (2000) Pre- and post-surgical Psycho-emotional aspects of the orthognathic surgery patient. Int. J. Adult. Orthod. Orthognath. Surg., 15, 16-23.

Brazier, J., Jones, N. \& Kind, P. (1993) Testing the validity of the Euroqol and comparing it with the SF-36 health survey questionnaire. Qual. Life Res., 2, 169-180.

Cunningham, S.J., Hunt, N.P. \& Feinmann, C. (1996) Perceptions of outcome following orthognathic surgery. $\mathrm{Br}$. J. Oral Maxillofac. Surg., 34, 210-213.

Cunningham, S.J., Garratt, A.M. \& Hunt, N.P. (2000) Development of condition-specific quality of life measure for patients with dentofacial deformity: I. Reliability of the instrument. Community Dent. Oral Epidemiol., 28 , 195-201.

Cunningham, S.J. \& Hunt, N.P. (2001) Quality of life and its importance in orthodontics. J. Orthod., 28, 152-158.

Cunningham, S.J., Garratt, A.M. \& Hunt, N.P. (2002) Development condition-specific quality of life measure for patients with dentofacial deformity: II. Validity and responsiveness testing. Community Dent. Oral Epidemiol., 30, 81-90.

Cushing, A.M., Sheiham, A. \& Maizels, J. (1986) Developing socio-dental indicators - the social impact of dental disease. Community Dent. Health, 3, 3-17.

Flanary, C.M., Barnwell, G.M., VanSickeles, J.E., Littlefield, J.H. \& Rugh, A.I. (1990) Impact of orthognathic surgery on normal and abnormal personality dimensions: a 2 year follow up study of 61 patients. Am. J. Orthod. Dentofac. Orthop., 98, 313-322.

Fukuhara, S., Suzukamo, Y., Bito, S. \& Kurokawa, K. (2001) Manual of SF-36 Japanese version 1, 2, Public Health Research Foundation, Tokyo, pp. 68-69.

Garratt, A.M., Ruta, D.A., Abdalla, M.I. \& Russel, I.T. (1994) SF-36 health survey questionnaire. responsiveness to changes in health status in four common clinical conditions. Qual. Health Care, 3, 186-192.

Garratt, A.M., Ruta, D.A., Abdalla, M.I. \& Russel, I.T. (1996) Responsiveness of the SF-36 and a condition-specific measure of health for patients with varicose veins. Qual. Life Res., 5, 1-12.

Gift, H.C. \& Redford, M. (1992) Oral health and the quality of life. Clin. Geriatr. Med., 8, 673-683.

Han, C.W., Yajima, Y., Nakajima, K., Lee, E.J., Meguro, M. \& Kohzuki, M. (2006) Construct validity of the frenchay activity index for community-dwelling elderly in Japan. Tohoku J. Exp. Med., 210, 99-107.

Hatch, J.P., Rugh, J.D., Clark, G.M., Keeling, S.D., Tiner, B.D. $\&$ Bays, R.A. (1998) Health-related quality of life following orthognathic surgery. Int. J. Adult. Orthod. Orthognath. Surg., 13, 67-77.

Kiyak, H.A., West, R.A., Hohl, T. \& McNeill, R.W. (1982) The psychological impact of orthognathic surgery: a 9 months follow-up. Am. J. Orthod., 81, 404-412.

Kiyak, H.A., Hohl, T., West, R.A. \& McNeill, R.W. (1984) Psychological changes in orthognathic surgery patients: a 24 month follow-up. J. Oral Maxillofac. Surg., 42, 506-512.

Kiyak, H.A., McNeill, R.W., West, R.A., Hohl, T. \& Heaton, P. 
(1986) Personality characteristics as predictors and sequelae of surgical and conventional orthodontics. Am. J. Orthod., 89, 383-392.

Kressin, N., Sprio, A., Bosse, R., Garcia, R. \& Kazis, L. (1996) Assessing oral health-related quality of life. Med. Care, 34, 416-427.

Laeo, A. \& Sheiham, A. (1996) The development of sociodental measure of dental impacts on daily living. Соттиnity Dent. Health, 13, 22-26.

Locker, D. (1988) Measuring oral health: a conceptual framework. Community Dent. Health, 5, 3-18.

Locker, D. \& Miller, Y. (1994) Evaluation of subjective oral health status indicators. J. Public Health Dent., 54, 167-176.

Nardi, P., Acocella, A., Tedesco, A., Rispoli, A. \& Giacomelli, E. (2003) Psychological aspects in orthognathic surgery. Body image and quality of life in post-surgical assessment. Body image and quality of life in post-surgical assessment. Minerva Stomatol., 52, 145-152, 152-155.

O’Brien, K., Kay, L., Fox, D. \& Mandall, N. (1998) Assessing oral health outcomes for orthodontics measuring health status and quality of life. Community Dent. Health, 15, 22-26.

Rispoli, A., Accocella, A., Pavone, I., Giacomelli, E., Ortiz, L. \& Scott, A.A. (2004) Psychological assessment changes in patients treated with orthognathic surgery: pre- and postsurgery report. World J. Orthod., 5, 48-53.

Shaw, W.C., Addy, M., Dummer, M.H., Ray, C. \& Frude, N. (1986) Dental and social effects of malocclusion and effectiveness of orthodontic treatment: a strategy for investigation. Community Dent. Oral Epidemiol., 14, 60-64.

Slade, G.D. \& Spencer, A.J. (1994) Development and evaluation of the oral health impact profile. Community Dent. Health, 11, 3-11.

Slade, G.D. (1997) Derivation and validation of a short-form oral health impact profile. Community Dent. Oral Epidemiol., 25, 284-290.

Slade, G.D. (1998) Assessing change in quality of life using the Oral Health Impact Profile. Community Dent. Oral Epidemiol., 26, 52-61.

Strauss, R.P. \& Hunt, R.J. (1993) Understanding the value of teeth to older adults: influences on the quality of life. $J$. Am. Dent. Assoc., 124, 105-110.

Ware, J.E. \& Sherbourne, C.D. (1992) The MOS 36-Item Short-Form Health Survey (SF-36). Conceptual framework and item selection. Med. Care, 30, 473-483.

Ware, J.E. (1993) Measuring patients' views: the optimum outcome measure. BMJ, 306, 1429-1430. 